\title{
Characterization of the merchant fleet in traffic in the Amazon basin using the Automatic Identification System (AIS)
}

\begin{abstract}
The objective of this article is to characterize the fleet of merchant ships that sail in the waters of the Amazon basin and carry the transport of commodities extracted in the region to other areas of Brazil and the planet. Ship behavior parameters will be evaluated through a statistical study of data obtained through automatic identification system (AIS) monitoring. The research methodology used is comparative and descriptive-analytical, considering the data captured in systematic monitoring with the aid of the Marine Traffic website to obtain the data of merchant ships registered in the Amazonian waters. The temporal horizon of the investigation comprises 24 months of the triennium (2016-2017-2018), encompassing qualitative and quantitative variables such as Ship Name, Ship Type, Flag, Tonnage, Length, Width, Speed, Port of Origin and Port of Destination. A comparison was made with the characteristics of the Merchant Ships of the world fleet in order to assist in choosing the most appropriate monitoring system to be used for the particular characteristics of the study region. After a detailed analysis of the activity of merchant ships in the Amazon Basin, we conclude that there is a high potential for the application of these technologies and studies of the behavior of Merchant Ships in the systematization of risk studies and preparation of the Brazilian states belonging to the Amazon Basin for possible incidents and catastrophes involving these vessels. We conclude in this article that the Amazonian merchant fleet is similar to that of the world fleet, observing the characteristics of inland navigation of small boats in the Amazon that is characteristic of this region.
\end{abstract}

Keywords: ship pollution, Amazonian biodiversity, sustainable environmental development, invasive species, collision of ships
Volume 8 Issue I - 2019

\author{
José Pinheiro Fragoso Neto Pereira,' Claudia \\ Ines Coelho de Souza, ${ }^{2}$ Alan Cavalcanti da \\ Cunha, ${ }^{3}$ Janilson Pequeno de Almeida,' Anne \\ Isabel Coelho Barbosa, ${ }^{4}$ Kellyane Silva da \\ Silva,' Lia Rafaela Carvalho Ferreira' \\ 'Environmental engineering, UEAP, Brazil \\ Lic QUIM, UEAP, Brazil \\ ${ }^{3}$ Environmental sciences, UNIFAP, Brazi \\ ${ }^{4}$ Eng QUIM, UEAP, Brazil
}

Correspondence: José Pinheiro Fragoso Neto Pereira, Environmental engineering, UEAP, Brazil, Email el_neton@hotmail.com

Received: February 20, 2019 | Published: February 27, 2019

\section{Introduction}

Accidents in waterways occur since the beginning of navigation. Navigation patterns came mainly as regulations to avoid collisions. The constant accidents resulted in efforts by the maritime industry to improve shipbuilding, reliability of navigation systems and the organization of operations on board to reduce the number of aquatic accidents.

The increasing global maritime traffic (four times more ships than in 1992, Tournadre, 2014) and shipping of petroleum products (ITOPF, 2015) makes it more difficult to reduce the environmental, economic and social risks caused by possible spills. The Automatic Identification System (AIS) technology provides real-time, meaningful information to support operational decision makers. ${ }^{1-10}$

The AIS is a messaging system originally designed to avoid collisions (AIS is mandatory for 300 GT ships and above for international travel, 500 GT and above for cargo not found in international waters and passenger vessels).

The vessel traffic and movement information collected can be exploited to predict the route of the ship at any given time. This is the process of predicting vessel movements well beyond any available positioning data, based on past vessel behaviors on the same route (PALLOTTA et al., 2013).

The environmental and socioeconomic issues associated with spills will always be a major topic: spill events are occurring, most of them unknown to the general public due to their small-scale impact, for example, half the total oil spills in the marine environment is from operational discharges and in most of these cases the discharges are illegal (GESAMP, 2007).

Some oil spills become media phenomena, due to their large size and environmental and socioeconomic impacts on local ecosystems and communities (LESCHINE, 2002). Planning and prevention of incident and collision incident management in waterways is extremely important in reducing and minimizing potential impacts. The latest scientific and technological developments in coastal monitoring and operational oceanography have provided the opportunity to build more complex and integrated decision support systems for risk management of this mode of transport

The increasing operational predictive capacity of marine meteorological conditions and a better understanding of the fate and behavioral processes of pollutants spilled along the waterways, along with the presence of advanced monitoring tools, can be integrated to provide a more secure support for decision making. Or plan issues associated with the risks of pollution from merchant shipping.

The development of a risk assessment approach integrating economic, environmental and social aspects combined with data from available surveillance monitoring systems is resulting in an innovative, holistic and sustainable approach for the maritime sector.

Merchant vessel variables used in risk calculations, derived from monitoring using AIS data such as speed, vessel type, weight (DWT), name and ID (MMSI or IMO number). 


\section{The Automatic Identification System (AIS) as a tool for monitoring merchant ships}

The International Maritime Organization (IMO) SOLAS convention was designed to ensure safety and life at sea, consisting of a set of international standards, first beginning in 1914 in response to the Titanic. In 2002, the Automatic Identification System (AIS) was created to be the standard of communication approved in all IMO member countries. Developed in the 1990s as a high-intensity, short-range identification and tracking network at the time, it was not expected to be detectable from space.

Composed of an automatic transponder operating in the maritime VHF range (a combination of a transmitter and a receiver that only operates on the international standard frequencies known as channels) AIS uses a technique similar to that of mobile telephony, where up to 4000 transponders exchange every minute on a single frequency, the operation does not require an operator and is considered automatic.

The greatest advantages of using AIS is time savings; quality of information (dimensions, position, heading, speed, final destination and load types for ground bases.); range of 40 nautical miles equivalent to $74.08 \mathrm{kilometers}$ and prevention of collisions between vessels. The AIS information received by VTS is important for accident investigation as it provides accurate historical data of time, identity, GPS-based position, compass heading, ground stroke, speed (per $\log / \mathrm{SOG}$ ), and turnaround rates precise information provided by the radar.

Working with a triangulation system, the transponder can be divided into two classes: Class A (complete performance planned for the equipment, mandatory use on all SOLAS ships); Class B (restricted functions, with a reduction in cost, not mandatory in vessels at the discretion of the national administrations). There are three types of equipment: Autonomous and continuous; limited reception capacity; extended transmission and reception capacity.

Analyzing the growing interest in using AIS as a navigational aid tool, in addition to operational use with the latest technologies, making it easier to handle equipment as an important tool, AIS is of paramount importance in large, medium and small vessels for better maritime traffic and the zeal of the lives around them. ${ }^{11-19}$

\section{Characteristics of the Amazon merchant fleet}

The time period of this investigation was 24 months of the triennium (2016-2017-2018), when checking the AIS data, with the aid of the website Marine Traffic, The amount of ship traffic was obtained. The graphic bar graph (02) which demonstrates the statistical results of the number and types of ships. A total of 3,919 vessels were checked during the survey period (Figure 1).

In graph (1) we have data from the world fleet of merchant ships, we can observe the predominance of dry cargoes where most are natural raw material movements, followed by a considered number of movements of the world oil merchant fleet which basically can be characterized by moving the world economy. We made a graph where it expresses the movement of the fleets of merchant ships in quarter within the Amazon region to make this regional comparison with the world-wide one (Figure 2).

From this survey, it was verified that most of the ships that entered the Amazon during the period of the survey are characterized as dry cargoes, these greater movements are of merchant ships that extract natural resources from the Amazon. Among them are the removals of eucalyptus chips by the company amapá forest and pulp s.a (amcel). The container vessel has a cargo volume equivalent to twenty feet (TEUs).

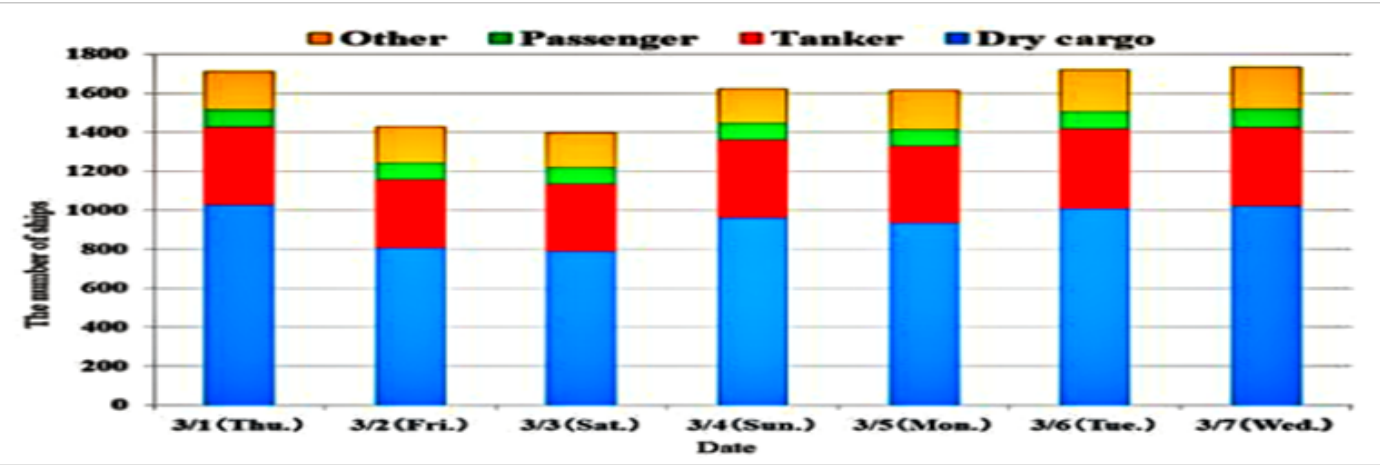

Figure I Quantity and types of ships in the world research area.

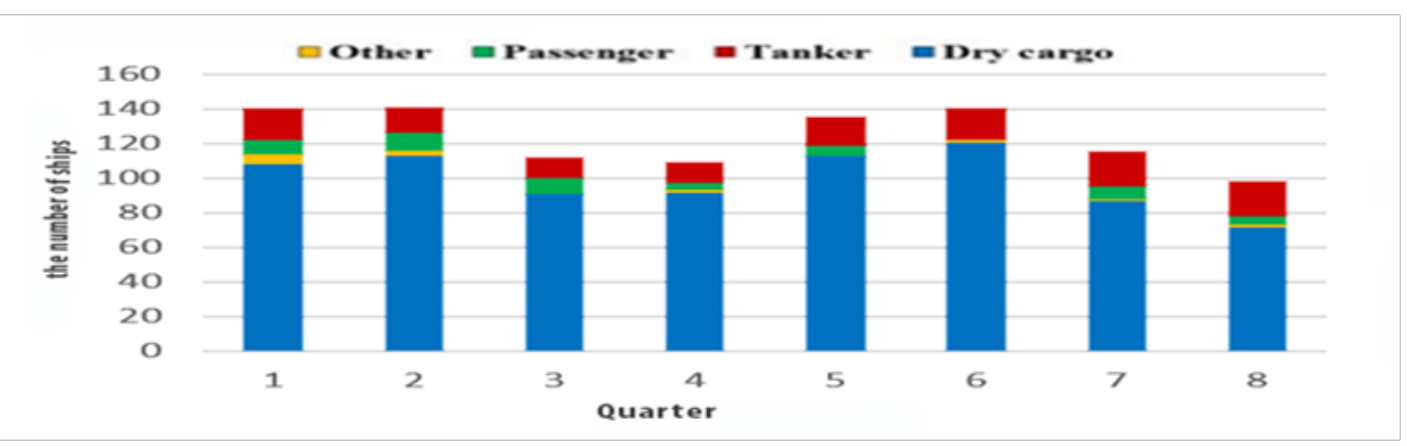

Figure 2 Quantity and types of vessels in the research area. 
The ships characterized as others in chart (02), were found to have had a smaller amount compared to the graphical world chart (01), due to the lower quantity of ports in the Amazon, to receive these national and international ships with several goods. Most of the ships entering the Amazon do not dock in the state of the amapá, they follow the way to other ports in the Amazon region, especially Santarém (PA), Manaus and Itacoatiara (both in Amazonas State). The ships that are stationed inside the polygon area of Santana Port, run by the CompanhiaDocas de Santana in front of Macapá, the ships are waiting in the polygonal area of the Amazonas river, waiting for the inspection authorities to do their work, such as Anvisa, Federal Police and the Navy, through the Captaincy of the Ports.

Few ships dock at the Port of Santana, among them are merchant ships without cargo, which comes to be loaded with wood chips from Amcel, the only product on the Amapá export agenda still in full swing. Since the Port of Zamin collapsed in 2014, killing six workers, the shipment of ore was compromised.

The other ships that station in front of Macapá follow the trip taking in their loads electronic products to the Free Zone of Manaus, often to take or to fetch grains of soybean and corn. One of the destinations of these foods is the Itacoatiara Port. With a flow of oil tankers in the Amazon almost the world average, the Amazon with only one oil pole located in the Amazon jungle, 650 kilometers from Manaus and is part of the Petrobras Exploration and Production Business Unit in the Solimões Basin, where exploration and production of oil and natural gas in the region. Throughout this year, Urucu's oil and gas production has represented $5 \%$ of the country's total production, currently around 2.3 million barrels equivalent.

In the graph to graph (02), we used 4 variable variables, oil tankers, dry loads and others. Tanker is a type of tanker used to transport crude oil and its by-products. It has efficiency to carry about 330 million liters of oil. Technology does much of the work. Its crew is on average 25 people, who stay all the way in the tower, located in the back of the ship. Thus, there is a large space for the cargo. It is in the tower that works the cabin of command and where are located areas like cabins and restaurant. In the Amazon region, it has a constant flow of tankers that run through the waters of the largest river in the world. Based on the data collected from this type of ship classified as an oil tanker, the year in which this type of vessel was built has its influences as the rich that can present if there is no maintenance according to the physical state of the vessel, it is worth noting that not all ships considered old are dangerous when there is a gauging of the care, from the internal and external state of the ship. In Table (1) we can observe the name of the ships, years of construction up to their status which is defined by the speed of the oil tanker that were monitored during the 2years. In these data, the risk that each ship presents is evident in the physical structures, from its length, width, weight (tonnage) and gross size of the ship. In these data we can distinguish their variation between gross tonnage and the ship's status that influence the balance of the weight of barrels and even the ship itself and its speed varies according to its course (Table 1).

Passenger Ship traffic, according to the second chart (02) is much smaller than the first chart (01), due to the number of ports that the Amazon region has, so there is an influence on the traffic flow of passenger ships. In the first graph (01) on a world scale there is a balance in the period of the ships' journeys of this classification, comparing with the second graph (02) we can relate the results obtained in the monitoring of the ship traffic in the Amazon region and relate the flow of results highlighting the number of ports in the region. Majority of these vessels are tourism agencies with the intention of making tourist routes between cities in the North region, the number of passengers and for this type of passage depend on the annual periods that cause greater movement for the flow of travel by the region, loading and unloading. It is possible to visualize in the graph that every quarter there is a diversified flow varying according to the years and months that were monitored during this research.

In the Amazon Region, this type of traffic is common due to the fact that the State of Amapa is not connected to other states of Brazil by road or rail, so the largest flow of tourist and commercial traffic is by waterway. The entrance of ships is easily accessible in the territory of the state of the Amapa due to a waterway that is in the mouth of the Amazon river in which any ship at state, national and international level through this entrance through the Atlantic Ocean. We can visualize through the data collected from the monitoring of ships that during the 13th month of the 2nd year there are flows of this type of ship with the data of the names of the ships, number of ships, flag, last port and destination of the same, variables used in the period and type of ship. We observed that most of these ships are of lines that maintains their route Macapa, Belem and Santana in the northern region of Brazil (Table 2). Ships suffer a remarkable wear over the years, for safety reasons, are removed from work. Then, the process of dismantling necessary to renew the naval activity begins.

A ship has an average life span of about 20 to 25 years. After that period, over time, ships have accumulated a lot of waste and rust from constant travel, shipping companies decide to replace them due to the high cost of maintenance. The polluting and dangerous habits of ship dismantling are the cause of great concern. At the end of their useful life, a large proportion of ships are scrapped in yards that resort to methods with considerable environmental and health impacts. These negative points prevent ship recycling from becoming a truly sustainable industry.

In graph (03) it presents a graph where it shows the numbers of merchant ships and their year of manufacture that entered the Amazon during the period of the research. In the monitoring, a number of ships with the dates of manufacture from 1948 to 1991 were verified at this Amazon entrance, knowing that with the shipping time the ships end up accumulating waste and rust on their routes, which can cause damage to their structure and to the environment. In the international sphere, ships that become waste are covered by the Basel Convention on Movement Control that extends beyond the boundaries of the Hazardous Wastes and their Disposal boundaries, dated March 22, 1989 , in which it was approved for ratification through Decree No. 37/93, of October 20 (Figure 3).

We verified in graph (03) the behavior of the renewal of ships that entered the Amazon during the survey. In this entry we verified boats with the date of manufacture from 1948 to 2017, with a larger number of ships with the most recent date, within the categories of manufacturing year the Amazon has a larger flow of new ships. Although efficient the system is still flawed here in the Amazon for lack of AIS towers. This greatly increases the risk of collisions, and a future increase in merchant vessel traffic may have a greater chance of incidents involving such vessels in those areas that lack AIS towers.

Merchant ships besides being able to cause accidents they are one of the biggest polluting agents that we have, the emission of $\mathrm{CO} 2$ of such a ship is equivalent to 83 thousand automobiles, taking into 
account a great fleet of ships by the Amazon region the pollution produced by them can be very large, in addition to fuel combustion we also have the use of ballast water that can bring microorganisms from different biomes to the Amazon region and can cause bio invasion and change natural aspects of the aquatic biome, an exotic species can have consequences as an ecological imbalance, which may also cause a possible loss of biodiversity, or change the characteristics of water such as acidification, among other peculiarities.

Table I Oil Tankers Monitoring data

\begin{tabular}{|c|c|c|c|c|c|c|c|}
\hline Name & Type & Year & Gross Tonnage & Gross Door & Length & Width & Status \\
\hline Ceylon & Tanker & 2002 & 28099 & 46001 & 179,88 & 32,2 & 11,6 knots \\
\hline Chelsea & Tanker & 2008 & 7218 & 8500 & 119,8 & 19 & 2,3 knots \\
\hline Chelsea & Tanker & 2008 & 7218 & 8500 & 119,8 & 19 & 13,1 knots \\
\hline Jenny & Tanker & 2002 & 28048 & 45861 & 179,88 & 32,2 & 14,6 knots \\
\hline Jenny & Tanker & 2002 & 28048 & 45861 & 179,88 & 32,2 & 12,8 knots \\
\hline Justice Express & Tanker & 2011 & 28725 & 45998 & 181,54 & 32,2 & 6,4 knots \\
\hline Justice Express & Tanker & 2011 & 28725 & 45998 & 181,54 & 32,2 & 16,6 knots \\
\hline Ceylon & Tanker & 2002 & 28099 & 46001 & 179,8 & 32,2 & 9,1 knots \\
\hline Ceylon & Tanker & 2002 & 28099 & 46001 & 179,8 & 32,2 & 12,9 knots \\
\hline Citrus Express & Tanker & 2006 & 31433 & 53688 & 186 & 35 & 12,6 knots \\
\hline Citrus Express & Tanker & 2006 & 31433 & 53688 & 186 & 35 & 13,3 knots \\
\hline Navig8 Adamite & Tanker & 2015 & 23676 & 37596 & 184,06 & 27,44 & 0 knots \\
\hline Ceylon & Tanker & 2002 & 28099 & 46001 & 179,8 & 32,2 & 9,5 knots \\
\hline Navig8 Adamite & Tanker & 2015 & 23676 & 37596 & 184,06 & 27,44 & 14,8 knots \\
\hline Ceylon & Tanker & 2002 & 28099 & 46001 & 179,8 & 32,2 & 12,3 knots \\
\hline Ocean Quest & Tanker & 1999 & 28547 & 47221 & 182,5 & 32,2 & 13,6 knots \\
\hline Ocean Quest & Tanker & 1999 & 28547 & 47221 & 182,5 & 32,2 & 10,5 knots \\
\hline Chemical Aquarius & Tanker & 2012 & 11383 & 18045 & 142,5 & 23 & 0 knots \\
\hline Chemical Aquarius & Tanker & 2012 & 11383 & 18045 & 142,5 & 23 & 15,7 knots \\
\hline Chemical Aquarius & Tanker & 2012 & 11383 & 18045 & 142,5 & 23 & 0 knots \\
\hline Alexandros M & Tanker & 2000 & 29351 & 48706 & 183 & 32,2 & 9,4 knots \\
\hline Alpine Link & Tanker & 2010 & 29826 & 50209 & 183 & 32,24 & 14,3 knots \\
\hline Alexandros M & Tanker & 2000 & 29351 & 48706 & 183 & 32,2 & 16 knots \\
\hline Chemical Aquarius & Tanker & 2012 & 11383 & 18045 & 142,5 & 23 & 0 knots \\
\hline Chemical Aquarius & Tanker & 2012 & 11383 & 18045 & 142,5 & 23 & 14 knots \\
\hline Alexandros M & Tanker & 2000 & 29351 & 48706 & 183 & 32,2 & 13,5 knots \\
\hline Vendome Street & Tanker & 2011 & 28778 & 47879 & 179,99 & 32,2 & 0 knots \\
\hline Vendome Street & Tanker & 2011 & 28778 & 47879 & 179,99 & 32,2 & 0 knots \\
\hline Vendome Street & Tanker & 2011 & 28778 & 47879 & 179,99 & 32,2 & 13,3 knots \\
\hline Vendome Street & Tanker & 2011 & 28778 & 47879 & 179,99 & 32,2 & 13,3 knots \\
\hline Alexandros M & Tanker & 2000 & 29351 & 48706 & 183 & 32,2 & 0 knots \\
\hline Alexandros M & Tanker & 2000 & 29351 & 48706 & 183 & 32,2 & 12,5 knots \\
\hline Torm Rosetta & Tanker & 2003 & 28567 & 47015 & 182,5 & 32,2 & 11,7 knots \\
\hline Torm Rosetta & Tanker & 2003 & 28567 & 47015 & 182,5 & 32,2 & 13,8 knots \\
\hline Ceylon & Tanker & 2002 & 28099 & 46001 & 179,8 & 32,2 & 11,2 knots \\
\hline
\end{tabular}

Source:Authors (2019). 
Table 2 Monitoring data of the 13th month for Passenger Ships.

\begin{tabular}{|c|c|c|c|c|c|}
\hline Ship Register number & Name & Flag & Type & Last port & Destination port \\
\hline 15 & N/M Breno & Brazil & Passenger & Belém (Brazil) & $\mathrm{N} / \mathrm{D}$ \\
\hline 65 & B/M Cidade & Brazil & Passenger & Belém (Brazil) & $\mathrm{N} / \mathrm{D}$ \\
\hline 15.2 & N/M Breno & Brazil & Passenger & Belém (Brazil) & $\mathrm{N} / \mathrm{D}$ \\
\hline 155 & Hanseatic & Bahamas & Passengers Ship & Belém (Brazil) & $\mathrm{N} / \mathrm{D}$ \\
\hline 15.3 & N/M Breno & Brazil & Passenger & Belém (Brazil) & $\mathrm{N} / \mathrm{D}$ \\
\hline 15.4 & N/M Breno & Brazil & Passenger & Belém (Brazil) & $\mathrm{N} / \mathrm{D}$ \\
\hline 167.1 & B/M Seamar III & Brazil & Passenger Ship & Santana (Brazil) & $\mathrm{N} / \mathrm{D}$ \\
\hline 15.5 & N/M Breno & Brazil & Passenger & Belém (Brazil) & $\mathrm{N} / \mathrm{D}$ \\
\hline 15.6 & N/M Breno & Brazil & Passenger & Belém (Brazil) & $\mathrm{N} / \mathrm{D}$ \\
\hline 15.7 & N/M Breno & Brazil & Passenger & Belém (Brazil) & $\mathrm{N} / \mathrm{D}$ \\
\hline 15.8 & N/M Breno & Brazil & Passenger & Belém (Brazil) & $\mathrm{N} / \mathrm{D}$ \\
\hline 15.11 & N/M Breno & Brazil & Passenger & Belém (Brazil) & $\mathrm{N} / \mathrm{D}$ \\
\hline 167.2 & B/M Seamar III & Brazil & Passenger Ship & Santana (Brazil) & $\mathrm{N} / \mathrm{D}$ \\
\hline 256.1 & João Gabriel & Brazil & Passenger & Icoaraci (Brazil) & Santana (Brazil) \\
\hline 60.4 & N/M Bruno & Brazil & Passenger & Santana (Brazil) & $\mathrm{N} / \mathrm{D}$ \\
\hline 167.3 & B/M Seamar III & Brazil & Passenger Ship & Santana (Brazil) & $\mathrm{N} / \mathrm{D}$ \\
\hline 15.12 & N/M Breno & Brazil & Passenger & Belém (Brazil) & $\mathrm{N} / \mathrm{D}$ \\
\hline 60.5 & N/M Bruno & Brazil & Passenger & Santana (Brazil) & $\mathrm{N} / \mathrm{D}$ \\
\hline 167.4 & B/M Seamar III & Brazil & Passenger Ship & Santana (Brazil) & $\mathrm{N} / \mathrm{D}$ \\
\hline 15.13 & N/M Breno & Brazil & Passenger & Belém (Brazil) & $\mathrm{N} / \mathrm{D}$ \\
\hline 167.5 & B/M Seamar III & Brazil & Passenger Ship & Santana (Brazil) & $\mathrm{N} / \mathrm{D}$ \\
\hline 167.5 & B/M Seamar III & Brazil & Passenger Ship & Santana (Brazil) & $\mathrm{N} / \mathrm{D}$ \\
\hline
\end{tabular}

Source:Authors (2019) 


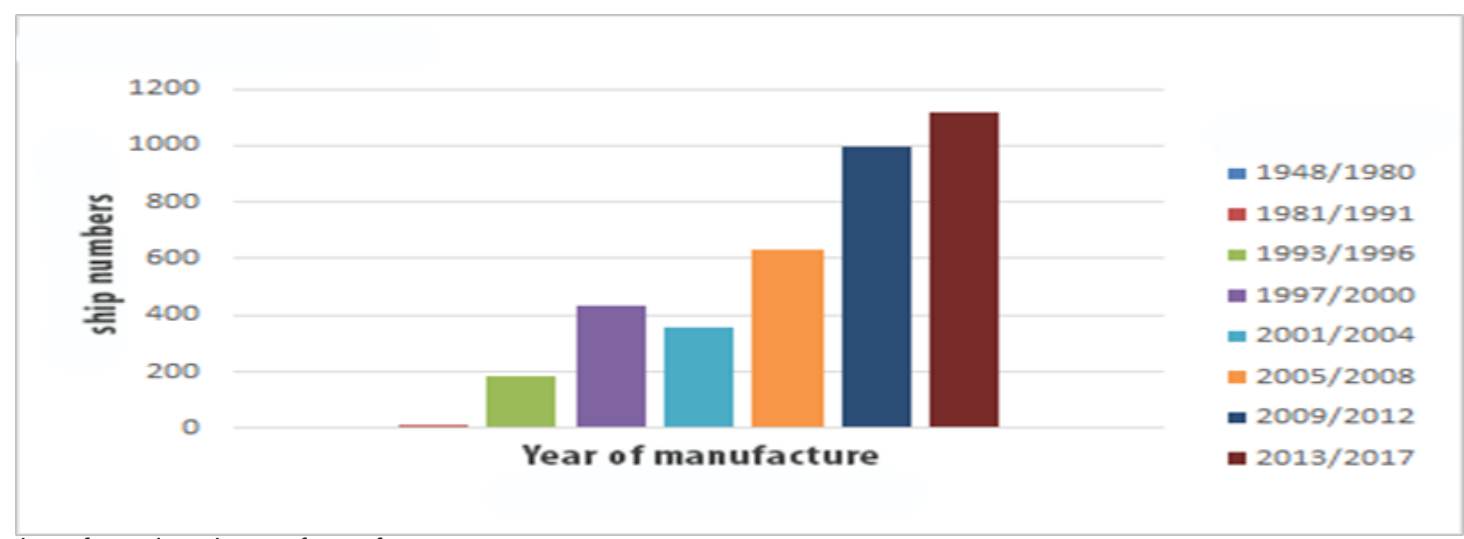

Figure 3 Number of vessels and year of manufacture.

Another problem that plagues merchant ships is drug trafficking, because it is much easier to transport drugs in containers because enforcement is more difficult and even if there is supervision it is not possible to check all the places knowing that a ship is large and has support for a large number of cargoes, not counting that the inspectors not to inspect the ships are submitted to receive "likes" so that there is no complaint, and unfortunately cases like this are frequent. And since most of the cases are omitted, drug trafficking on ships becomes a topic that goes unchallenged because theoretically "it does not happen."

It is common the traffic of passenger ships in the Amazon region due to the state of Amapa not having access to other states by road, so the means to go to other states is through this means of transportation. One of the problems of passenger ship traffic is the security that people who use this type of transport run, because without the data of unknown ships the ease of crossing with pirate ships is great.

There is a great index in the Amazon region of cases of piracy in the largest river in the world, a factor that takes away the beauty of the Amazon, the violence in waterways are not news for those who make this journey monthly security in these ways is also of extreme necessity since, directly affects the consumer and the consumer. Due to the fact that the Amazon region has a great extension of fluvial areas, its access is very easy due to the lack of monitoring of entrances and exits of ships, from the big freighters to the small ship like the other types of fishing vessels. The lack of knowledge of the names of ships, records and routes is one of the risks presented in the Amazon, making it difficult for those who traffic on waterways.

The abandonment of ships is one of the main problems for the environment, because, there are several factors that contribute to directly affect nature, one of these factors is the chemical means that through the rust of the ship's metallic structure, there is a change in natural behavior of the affected area. There is also another factor that has a direct interaction of these abandoned ships that are the riverside towns that coexist in these regions and often withdraw all the metallic material to take advantage of that matter.

One of the reasons that cause this action is the investment of equipment maintenance for the ship is appropriate to travel, taking into account the age of the ship the oldest are the ones that are in a higher state of abandonment due to the requirements of the legislation of the flags of countries of each ship, some countries are rigid as the factors described as environmental and social problems. The risk of accidents by shipwrecks is also one of the problems for the course of a line of passenger ships and cargo ships.

In the northern region of Brazil, specifically the Amazon region has large waterways, the flow of freighters and passengers are constant, also having a flow of unknown ships that are considered as fleet risks due to the non-identification of the vessel and because there are no means of inspection of all this area, there is a possibility that this practice of abandoning ships exists in this region.

\section{Final considerations}

The present article alludes to the monitoring of vessels, through a tower in earth that triangulates with the system AIS (Automatic Identification System) present in the ships, divided in two classes being: Class A and Class B, respectively, equipment mandatory on all ships and not mandatory on vessels with cost reduction.

However, in the region of our field of research the equipment is only available in one unit, which is located in the Amazon region more specifically in Belem, but we know the size of fluvial territory so that it has the field of study effective, needs of its implementation and the research object.

Thus, it is limited to address other important points due to the lack of information in a certain period of time that the equipment does not pass data such as: type of vessel, speed, contact between ship and the tower, this knowledge acquired in the article proved to be important for logistics and the operation of the material due to the lack of scientific research in the Amazon region.

With this, it is worth mentioning that each chart has its specifics as it was quoted during the course of the work, for example: when speaking the types of vessel and its particular function, as graph 02 demonstrated a certain amount for a certain period of time that at the end resulted in 3919 vessels during the time of research. It was verified that a great part of the movement is of raw materials in ships with dry loads.

Already bringing to our reality, we can see in the graph that most of the data is of dry loads (containers), that the other means present a certain lack due to the lack of infrastructure; the Amazon region is bathed by a hydrographic basin which facilitates the transition of ships for freight transport facilitating the flow of crude raw material to various regions of the world. In this way, research and improvement is fundamental for the evolution of the region. 
The characterization of merchant ships in the Amazon is extremely important to identify potential types of problems to be faced, also to alert and prevent risks and damages that may occasionally occur.

\section{Acknowledgments}

We thank theUniversity of the State of Amapa-UEAP, its faculty and administration, which provided us with this opportunity. We also thank the Federal University of the State of Amapa-UNIFAP that enabled us to have a whole structure for this research. In particular, we thank our counselor Jose Pinheiro Fragoso Neto Pereira who has made no effort to help and support us, always believing in our potential. We also thank Bionorte and all those involved.

\section{Conflicts of interest}

Author does not have any conflicts of interest.

\section{References}

1. AIS, Automatic Identification System: MANDO 301/303 AIS Embedded Modules AIS Monitoring and Control Station. 2012.

2. AIS, transponders: Regulations for carriage of AIS. 2018.

3. AIS, Automatic Identification System. 2018

4. Balduzzi, Marco; PASTA, Alessandro; WILHOIT, Kyle. A Security Evaluation of AIS Automated Identification System. 2018.

5. DGRM. Directorate-General for Natural Resources, Safety and Maritime Services. 2018.

6. FREAIS Veel tarcking. AIS data sharing and vessel tracking by AIS Hub. 2018
7. GESAMP: Joint Group of Experts on the Scientific Aspects of Marine Environmental Protection (GESAMP) - Report No. 75 "Estimates of Oil Entering the Marine Environment from Sea-Based Activities. 2007.

8. http://www.itopf.com/fileadmin/data/Documents/Company_it/Oil_ Spill_Stats_2014FINALlowres.pdf

9. Leschine TM. Oil spills and the social amplification and attenuation of risk. Spill Sci. Technol. B. 2002;7, 63-73.

10. Marine traffic. Marine traffic Disponível em.

11. Standards of Maritime Authority for Navigation and Nautical Charts: Normam 28/Dhn. 2011.

12. OEC. The United States is the 2nd largest export economy in the world. 2018.

13. ORBCOMM. AIS satellite tracking for vessels. 2018.

14. Pallotta G, Vespe M, Bryan K. Vessel pattern knowledge discovery from ais data: A framework for anomaly detection and route prediction. Entropy.2013; 15. 2218-2245.

15. PELICANO. The End of a Ship's Life. 2018.

16. Royal Fic. All about oil tankers. 2018.

17. Selesnafes. $\mathrm{n}$ front of Macapá, ships line up on the Amazon River. 2018.

18. Tournadre J. Anthropogenic pressure on the open ocean: the growth of ship traffic revealed by altimeter data analysis. Geophys. Res. Let. 2014;41.7924-7932.

19. Types of Automatic Identification Systems (Per Itu-R M.1371 And Iec Standards). 2018. 